\title{
КИНЕТИЧЕСКИЙ АНАЛИЗ ГИДРОКСИЛЬНОГО МЕХАНИЗМА АНТИМАЛЯРИЙНОГО ДЕЙСТВИЯ АРТЕМИЗИНИНА
}

\author{
Е.Т. Денисов, Т.Г. Денисова \\ ФГБУН Институт проблем химической физики РАН, \\ 142432, Россия, Черноголовка, просп. акад. Семенова 1.
}

DOI: 10.19163/MedChemRussia2021-2021-494

E-mail:denisova@icp.ac.ru

Артемизинин (А) и его производные успешно применяются против малярийного плазмодия Plasmodium falciparum, устойчивого по отношении к хинину и его аналогам [1]. Лечебное действие А связано с генерированием свободных радикалов [1]. Пероксидный мостик в структуре А и его производных по реакции с хелатами двухвалентного железа, входящими в состав ферментов, генерирует свободные радикалы, что приводит к гибели паразита. Испытание на антималярийную активность аналогов А различного строения показало, что важную роль играет вся структура молекулы А, а не только его пероксидный мостик [1, 2]. Ниже приведены структуры А и ряда производных 10-дигидроартемизинина, которые взяты в качестве объектов кинетического анализа [3].

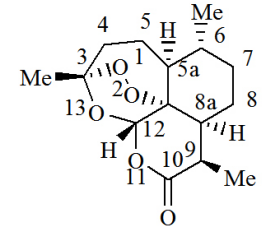

Артемизинин (А)

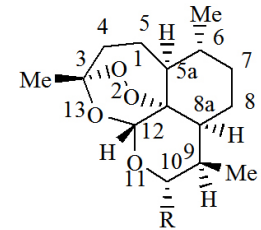

Производные 10-дигидроартемизинина:

$\mathbf{B}-\mathrm{R}=\mathrm{CH}_{2} \mathrm{CH}_{2} \mathrm{OCH}_{2} \mathrm{C}_{6} \mathrm{H}_{4} \mathrm{~F}\left(\mathrm{CF}_{3}\right), \mathbf{C}-\mathrm{R}=$

$\mathrm{CH}_{2} \mathrm{CH}_{2} \mathrm{OC}(\mathrm{O}) \mathrm{C}_{6} \mathrm{H}_{4} \mathrm{~F}\left(\mathrm{CF}_{3}\right), \mathbf{D}-\mathrm{R}=\mathrm{OC}_{6} \mathrm{H}_{4} \mathrm{~F}\left(\mathrm{CF}_{3}\right)$.

Для 13 производных 10-дигидроартемизинина, содержащих фторзаместители (F и CF3), построены кинетические схемы внутримолекулярного окисления. Все стадии кинетической схемы охарактеризованы энтальпией, с использованием модели пересекающихся парабол (МПП), вычислены их энергии активации и константы скорости. Учтена конкуренция моно- и бимолекулярных радикальных реакций. По эмпирической зависимости антималярийной активности IC50 от числа гидроксильных радикалов $\mathrm{nOH}$, генерируемых соединением, вычислена антималярийная эффективность каждого препарата.

Работа выполнена по теме Государственного задания, № государственной регистрации ЦИТИС АААA-A19-119071190045-0.

\section{Литература}

[1] E. Denisov, S. Solodova, and T. Denisova, Russ. Chem. Rev. 2010, V. 79, No. 11, P. 981.

[2] E. Denisov, Org. Biomol. Chem. 2011, V, 9. No. 11, P. 4219.

[3] E. Denisov, and T. Denisova, Kinet. Catal. 2015, V. 56, No. 3, P. 285.

$$
-494-
$$

